\title{
Classification, diagnosis of reversibility and severity assessment of patients having respiratory distress based on pulmonary function test
}

\author{
Ghosh S. ${ }^{1}$, Gayen P. ${ }^{2 *}$
}

DOI: https://doi.org/10.17511/ijmrr.2020.i01.05

\footnotetext{
${ }^{1}$ Saswata Ghosh, Associate Professor, Department of Chest Medicine, Malda Medical College, Malda, West Bengal, India.

2* Prosenjit Gayen, Associate Professor, Department of Pathology, Raiganj Government Medical College and Hospital, Raiganj, West Bengal, India.
}

Introduction: Pulmonary function testing is the gold standard for physicians to diagnose and manage respiratory problems. An obstructive defect is indicated by low forced expiratory volume in one second/forced vital capacity (FEV1/FVC) ratio, defined as less than 0.7 or below the fifth percentile. If an obstructive defect is present, the physician should determine if the disease is reversible based on the increase in FEV1 or FVC after bronchodilator treatment (i.e., increase of more than $12 \%$ and $200 \mathrm{ml}$ in adults). An FVC below the fifth percentile indicates a restrictive pattern based on NHANES III data in adults. If both the FEV1/FVC ratio and the FVC are low, the patient has a mixed defect. Method: A total of 60 patients having respiratory distress, who attended chest OPD underwent a pulmonary function test. Results: In this study out of 60 patients, 32 patients had obstructive airway diseases with low FEV1/FVC (53.33\%), 8 of them (13.33\%) had restrictive lung diseases, ten patients(16.66\%) had mixed features and rest ten patients(16.66\%) had normal spirometry. Among those 32 patients of obstructive features, 22 (68.75\%) had reversible airway diseases. Severity was measured among the other ten non-reversible obstructive patients according to the GOLD criteria. Conclusion: Pulmonary function test is the fundamental first-line investigation to diagnose obstructive and restrictive lung diseases and also to differentiate between reversible and non-reversible obstruction. It is also a vital tool for determining the severity among non-reversible obstructive airway patients.

Keywords: Pulmonary function test, Obstructive airway disease, Restrictive lung disease

Corresponding Author

Prosenjit Gayen, Associate Professor, Department of Pathology, Raiganj Government Medical College and Hospital, Raiganj, West Bengal, India. Email: prosenjitdr@gmail.com
How to Cite this Article

To Browse

Ghosh S, Gayen P. Classification, diagnosis of reversibility and severity assessment of patients having respiratory distress based on pulmonary function test. Int J Med Res Rev. 2020;8(1):31-39. Available From https://ijmrr.medresearch.in/index.php/ijmrr/article/ view/1117

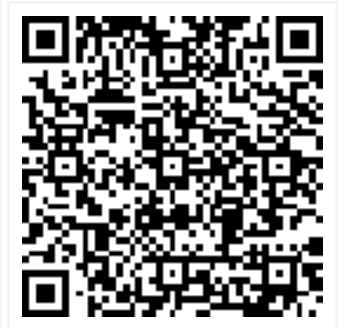

Manuscript Received 2019-12-26

Conflict of Interest No
Review Round 1 2020-01-06

Funding Nil
Review Round 2 2020-01-14

Ethical Approval Yes
Review Round 3

Accepted 2020-01-20

Plagiarism X-checker $6 \%$

(c) 2020 by Saswata Ghosh, Prosenjit Gayen and Published by Siddharth Health Research and Social Welfare Society. This is an Open Access article licensed under a Creative Commons Attribution 4.0 International License https://creativecommons.org/licenses/by/4.0/ unported [CC BY 4.0]. 


\section{Introduction}

Pulmonary function testing (PFT) is a powerful tool for primary care physicians to diagnose and manage respiratory problems.

An obstructive defect is indicated by a low forced expiratory volume in one second/forced vital capacity (FEV1/FVC) ratio, which is defined as less than $70 \%$ or below the fifth percentile based on data from the Third National Health and Nutrition Examination Survey (NHANES III) in adults, and less than $85 \%$ in patients five to 18 years of age.

If an obstructive defect is present, the physician should determine if the disease is reversible based on the increase in FEV1 or FVC after bronchodilator treatment (i.e., increase of more than $12 \%$ in patients five to 18 years of age, or more than $12 \%$ and more than $200 \mathrm{~mL}$ in adults).

A restrictive pattern is indicated by an FVC below the fifth percentile based on NHANES III data in adults, or less than $80 \%$ in patients five to 18 years of age.

If a restrictive pattern is present, full pulmonary function tests with the diffusing capacity of the lung for carbon monoxide testing should be ordered to confirm restrictive lung disease and form a differential diagnosis.

If both the FEV1/FVC ratio and the FVC are low, the patient has a mixed defect. The severity of the abnormality is determined by the FEV1 (percentage of predicted) [1].

Indications: Pulmonary function tests (PFTs) are useful for diagnosing the cause of unexplained respiratory symptoms and monitoring patients with known respiratory disease. Many organizations, including the National Asthma Education and Prevention Program, Global Initiative for Chronic Obstructive Lung Disease (GOLD), and American Thoracic Society (ATS), recommend using these tests $[2,3,4]$.

PFTs take approximately 15 minutes for adults, 15 to 30 minutes for children, 45 minutes for pre and post-bronchodilator testing, Five years is usually the youngest age at which children can cooperate with PFT procedures.

\section{Procedure}

01. The patient will be asked to place a mouthpiece attached to the spirometer in his mouth. It is essential to make a tight seal with his lips so all
Of the air will go into the spirometer to be measured. The patient will also wear nose clips to keep air from leaking out of your nose.

02. After breathing normally patient will be asked to blow out until his lungs are empty slowly.

03. Then they will take a big, deep breath to fill up their lungs completely.

04. As soon as their lungs are full, they will blow out as hard and as fast as you can until their lungs are empty.

05. They will be asked to repeat the test until there are three reasonable efforts.

06. If an obstructive defect is present, the patient is given 200 mcg Levosalbutamol via MDI and the test is repeated after 15 minutes to assess the reversibility.

This test allows us to measure:

- Forced Vital Capacity (FVC) - the amount of air one can force out of his lungs after a maximum inspiration

- Forced Expiratory Volume in the first second (FEV1)

- Peak Expiratory Flow Rate (PEFR) - how fast one can blow out the air in your lungs

- Forced Inspiratory Vital Capacity (FIVC) - the amount of air one can take into your lungs

- The shape of your Flow Volume Loop (FVC + FIVC) also provides information to us.

\section{Getting Started}

Before PFT results can be reliably interpreted, three factors must be confirmed:

(1) The volume-time curve reaches a plateau, and expiration lasts at least six seconds;

(2) Results of the two best efforts on the PFT are within $0.2 \mathrm{~L}$ of each other; and

(3) The flow-volume loops are free of artefacts and abnormalities [.5] If the patient's efforts yield flattened flow-volume loops, the submaximal effort is most likely; however, central or upper airway obstruction should be considered.

\section{Aims and Objectives}

Step 1: To determine if the FEV1/FVC ratio is low, thereby confirming the obstructive pattern.

Step 2: To determine if the FVC is Low 
Step 3: To confirm the restrictive pattern

Step 4: To grade the severity of the abnormality by the value of FEV1

Step 5: To determine reversibility of the obstructive defect based on the increase in FEV1 or FVC after bronchodilator treatment (i.e., increase of more than $12 \%$ and $200 \mathrm{~mL}$ in adults).

\section{Methods}

Study type: Hospital-based cross-sectional observation study.

Sample size: Total of 50 patients having respiratory distress have been enrolled.

\section{Inclusion criteria:}

01. Patients having respiratory distress

02. Patients above 18 years of age

03. Patients who gave written consent for the procedure.

\section{Exclusion criteria:}

01. Patients not having Pulmonary Tuberculosis

02. Patients below 18 years of age

03. Patients not giving consent for the procedure.

Sample size: 50

Study area: OPD, Department of Respiratory Medicine, Malda Medical College, Malda, WestBengal, India

Study population: Patients having respiratory distress attending the above said OPD.

\section{Tools of study:}

01. Computer

02. PFT software

03. Spirometer

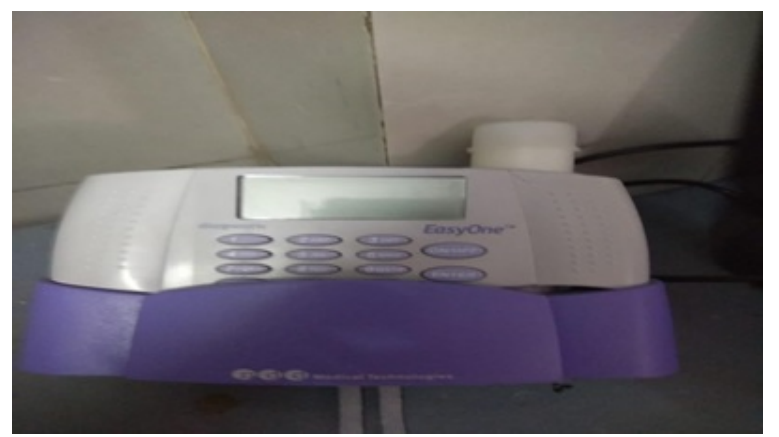

Fig-1: Spirometer used in the current study.
04. Printer

05. Disposable mouthpiece

06. Disposable nose piece

07. A 3-L syringe for calibration

\section{Results}

A total of 60 patients above 18 years of age having respiratory distress were included in the study.

Pulmonary function tests with bronchodilator reversibility were done among those patients after taking their consents.

The key borderline characteristics are listed in Table 1.

\section{Table-1: Distribution of PFT outcome.}

\begin{tabular}{|l|l|l|l|l|}
\hline \multicolumn{1}{|c|}{ PFT Outcome } & Male & Female & Total & Percentage \\
\hline Normal & 6 & 4 & 10 & 16.66 \\
\hline Abnormal & 36 & 14 & 50 & 83.34 \\
\hline
\end{tabular}

Figure 1 represents Age distribution among the patients having abnormal PFTs shows that maximum numbers of them are in the age group 31-50 years (total 21 patients, 42\%) followed by group of $18-30$ years (Total 12 patients, $24 \%$ ).

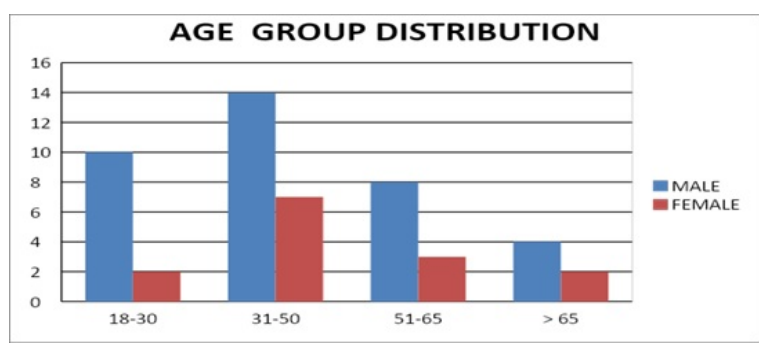

Fig-1: Age group distribution.

Among 50 patients, 36 were males (72\%) and the rest 14 was females (28\%).

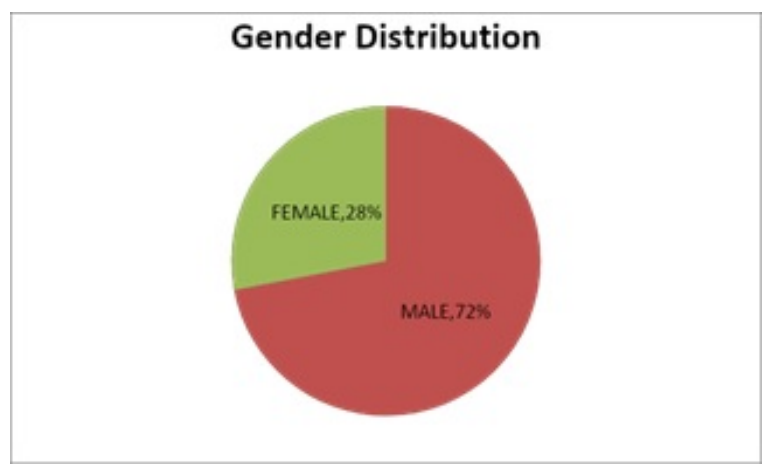

Fig-2: Gender distribution of patients with abnormal PFT. 


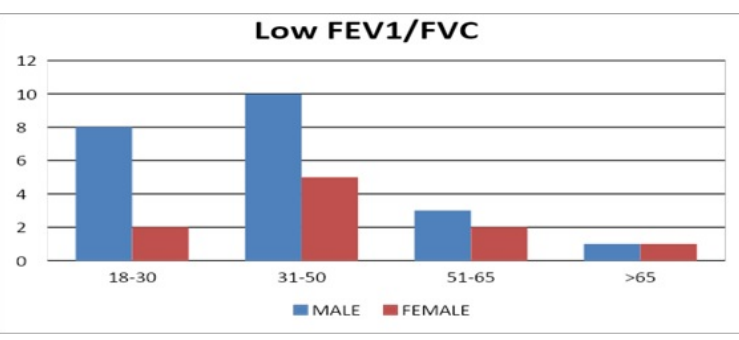

Fig-3: Among all patients, 32 patients found to have low FEV1/FVC $(64 \%)$, maximum in the age group of 31-50.
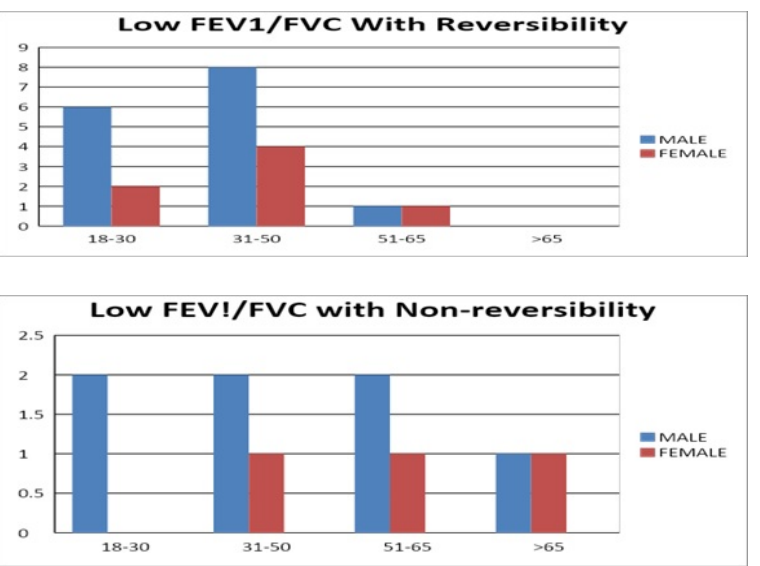

Fig-4 and 5: Among those 32 patients, 22 of them $(68.75 \%)$ found to have reversible airway diseases (more than $200 \mathrm{ml}$ and $12 \%$ increase in FEV1), rest 10 patients showed non-reversibility.

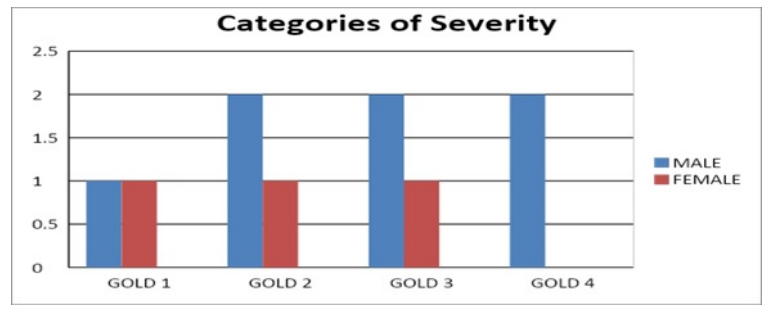

Fig-6: Categorization of severity in nonreversible obstructive airway diseases (mainly COPD) according to GOLD criteria $(n=10)$.

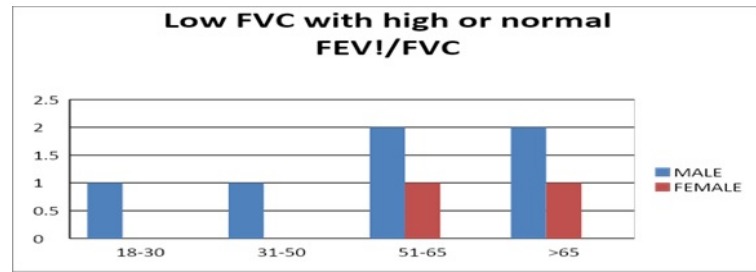

Fig-7: Age sex distribution of Restrictive lung diseases (low FVC with high or normal FEV1/FVC) $(n=8)$.

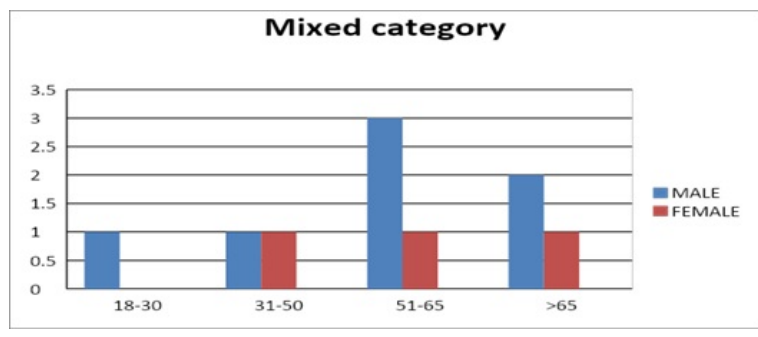

Fig-8: Age sex distribution of patients having mixed obstructive and restrictive features $(n=10)$.

\section{Discussion}

The present study has been compared with those of the other reviews of the pulmonary function test and its various implications. The present study has a few critical observations. Out of 60 patients of breathlessness that had undergone PFT, 50 of them $(83.33 \%)$ showed abnormalities in lung function.

The comparison of outcomes between symptomatic individuals with and without the chronic obstructive pulmonary disease (COPD) has been one of the many research questions posed in an American Thoracic Society/European Respiratory Society statement [6]. It represents the main thrust of this Pulmonary Perspective.

Gender difference has a significant impact in society among the patients of breathlessness. In a study conducted by Shiva D. Rahmanian et al, it was found that the majority of the participants were male $(87.6 \%)$. There was a significantly higher percentage of cough and phlegm production in males.

There was also a lower FEV1 and a higher RV in males than females [7]. It is in accordance with the present study where it was founded that $72 \%$ of patients with abnormal PFTs are male, rest $28 \%$ are females.

A large study conducted by Dr Earl S. Ford et al to look for trends in the prevalence of obstructive and restrictive lung function among adults in the United States, it was found that during 2007-2010, $13.5 \%$ (SE, 0.6) of participants had evidence of airway obstruction (FEV1/FVC, <0.70): $79.9 \%$ of adults had normal lung function, $6.5 \%$ had a restrictive impairment, $7.5 \%$ had mild obstruction, $5.4 \%$ had moderate obstruction, and $0.7 \%$ had severe obstruction [8].

In another large study conducted by J. Vandevoorde et al which was subsequently published in European 
Respiratory Journal, it was shown that prevalence of Obstructive lung diseases were about $45.9 \%$, rest $54.1 \%$ were patients with Restrictive and mixed pattern [9]. This goes in contrary to the present study where $64 \%$ of patients diagnosed with obstructive features; the rest $36 \%$ had either restrictive or mixed diseases. Ferguson GT et al had one similar study of spirometry among obstructive airway patients [10].

Regarding the determination of reversibility, the choice of inhaler device is crucial since suboptimal inhalation technique may influence the result. On the other hand, the bronchodilator response also varies from time to time and may depend on patient characteristics. In the present study, reversibility was tested with $400 \mu \mathrm{g}$ salbutamol metered dose inhaler.

Testing of airway reversibility is an essential diagnostic tool when investigating patients with obstructive airway diseases, particularly in patients with asthma. Traditionally, asthma has been considered a reversible airway disease in contrast to COPD. However, in recent years, it has been recognized that many patients with a clinical diagnosis of COPD, and without signs of asthma, may exhibit considerable reversibility when tested with rapid-acting $\beta 2$-agonists [11].

One study by Veronika Müller et al showed that despite maintenance treatment considered to be adequate for good management of the patients, 121 $(80 \%)$ of the originally included 151 patients demonstrated airway obstruction. Of those 121 patients, 41 (34\%) demonstrated reversibility according to ATS/ERS guidelines when tested with $400 \mu \mathrm{g}$ salbutamol; 21 patients with COPD (33\%), two with ACOS (17\%), and 18 with asthma (39\%) [12].

Another study by Postma DS et al clearly showed the differences between reversible and irreversible obstruction on the basis of reversibility criteria. [13]. Bronchodilator reversibility in asthma and COPD: Findings from three large population studies - a large study which was conducted by Christer Janson et al and was published in European Respiratory Journal showed more or less similar result [14].

In the present study, among 32 patients of obstructive features, 22 patients $(68.75 \%)$ found to have reversible airway diseases (more than $200 \mathrm{ml}$ and $12 \%$ increase in FEV!), rest 10 (31.25\%) did not show reversibility.
In restrictive lung disease, both forced expiratory volume in one second (FEV1) and forced vital capacity (FVC) are reduced, however, the decline in FVC is more than that of FEV1, resulting in a higher than $80 \%$ FEV1/FVC ratio. This indicates that the FVC is also reduced, but not by the same ratio as FEV1. Barreiro TJ et al, in their study precisely provided a stepwise approach for the interpretation of spirometry [15].

In their research they pointed out that Spirometry is a powerful tool that can be used to detect, follow, and manage patients with lung disorders. Technology advancements have made spirometry much more reliable and relatively simple to incorporate into a routine office visit.

However, interpreting spirometry results can be challenging because the quality of the test is largely dependent on patient effort and cooperation, and the interpreter's knowledge of appropriate reference values.

A simplified and stepwise method is key to interpreting spirometry. The first step is determining the validity of the test. Next, the determination of obstructive or restrictive ventilatory pattern is made. If a ventilatory pattern is identified, its severity is graded. In some patients, additional tests such as static lung volumes, diffusing capacity of the lung for carbon monoxide, and bronchodilator challenge testing are needed.

These tests can further define lung processes but require more sophisticated equipment and expertise available only in a pulmonary function laboratory. Aaron SD et al demonstrated in their study the accuracy of diagnosing restrictive lung diseases by pulmonary function test [16].

They concluded that Spirometry is very useful at excluding a restrictive defect. When the VC is within the normal range, the probability of a restrictive defect is $<3 \%$, and unless restrictive lung disease is suspected a priori, measurement of lung volumes can be avoided.

However, spirometry is not able to accurately predict lung restriction; $<60 \%$ of patients with a classical spirometric restrictive pattern had pulmonary restriction confirmed on lung volume measurements. For these patients, measurement of the TLC is needed to confirm a true restrictive defect.

The current study found 8 patients of restrictive lung diseases (16\%) having low FVC with high or 
Normal FEV1/FVC whereas 10 patients (20\%) having a mixed pattern of both obstructive and restrictive features among all 50 patients of abnormal pulmonary functions.

Reduction of FEV1\%FVC ratio together with lowered FVC often is interpreted as "mixed" ventilatory disturbances. A retrospective, cross-sectional analysis of pulmonary function tests for the mixed variety was done by Boros $P$ et al [17].

They found that only $17 \%$ of the patients had a mixed pattern which tallies with the present study where $20 \%$ patients exhibited mixed characteristics. There was also an inverse correlation between FEV $1 \%$ predicted and RV\% TLC\% predicted ratio. So, the basic mechanism of reduction in VC and FVC in patients with normal TLC is increased RV.

They concluded that "Mixed" ventilatory impairment in majority cases represents airway obstruction with lung hyperinflation. Such a coincidence of reduced FVC and FEV1\%FVC ratio requires further investigations (plethysmography) to clarify the reason for the diminished vital capacity.

Regarding the assessment of the severity of nonreversible obstructive airway diseases (mainly COPD), GOLD criteria were followed. In the present study, the majority of the patients fell under GOLD 2 and GOLD 3 stages ( $30 \%$ each). Mapel DW et al performed a multicenter, cross-sectional, observational study conducted in 83 primary care clinics from across the United States.

A total of 899 patients with a clinical diagnosis of chronic obstructive pulmonary disease completed a questionnaire and spirometry testing. They concluded that Physicians' chronic obstructive pulmonary disease severity ratings before spirometry were accurate for only $30 \%$ of patients with evaluable spirometry results, and disease severity in $41 \%$ of patients was underestimated.

Physicians also underestimated severity compared with patients' self-assessment among $42 \%$ of those with evaluable results. After spirometry, physicians changed their opinions on the severity of $30 \%$ of patients and recommended treatment changes for $37 \%$. [18]. In a study performed by Katherine A. Safka et al regarding GOLD Stage and Treatment in COPD, it was observed that a total of $8.2 \%$ of patients were in the GOLD group $A, 28.3 \%$ in group $B, 4.2 \%$ in group $C$ and $59.2 \%$ in group $D$. needless to say that patients' GOLD classification was determined based on symptoms (modified Medical
Research Council [mMRC] dyspnea scale, COPD Assessment Test [CAT]), spirometry and selfreported exacerbation history [19]. TA study of the distribution of COPD in UK general practice using the new GOLD classification by John Haughney et al, data for 9219 COPD patients were collected.

For the 6283 patients with both forced expiratory volume in $1 \mathrm{~s}$ (FEV1) and modified Medical Research Council scores (mean \pm sd age $69.2 \pm 10.6$ years,

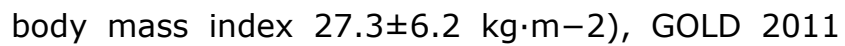
group distributions were: A (low risk and fewer symptoms) $36.1 \%$, B (low risk and more symptoms) $19.1 \%$, C (high risk and fewer symptoms) $19.6 \%$ and D (high risk and more symptoms) $25.3 \%$.

This is in contrast with GOLD 2007 stage classification: I (mild) $17.1 \%$, II (moderate) $52.2 \%$, III (severe) $25.5 \%$ and IV (very severe) 5.2\%. 20\% of patients with FEV $1 \geq 50 \%$ predicted had more than two exacerbations in the previous 12 months. $70 \%$ of patients with FEV $1<50 \%$ pred had fewer than two exacerbations in the previous 12 months [20].

\section{Limitations}

01 . Small numbers of patients were included in the study.

02. DLCO could not be performed among patients with high FEV1/FVC to confirm restrictive lung diseases.

\section{Conclusions}

- Prevalence of respiratory distressed patients are more among males than females.

- Prevalence is also more in the middle age group.

- Obstructive variety is much more prevalent than others.

- Among obstructive airway diseases, reversible features are much more prevalent, more so in younger age group.

\section{What the study adds to the existing knowledge}

There is not much difference in the prevalence among restrictive and mixed varieties. nonreversible obstructive airway diseases. Among the non-reversible obstructive airway diseases, severity classes of GOLD 2 and GOLD 3 are more prevalent 
Than others.

\section{Author's contribution}

Dr. Saswata Ghosh and Dr. Prosenjit Gayen: Concept designing, conducting the study and writing the manuscript.

\section{Reference}

01. Jeremy DJ, MD, MPH. Tripler Army Medical Center, Honolulu, HawaiiWesley M, Theurer, do, mph, Madigan Army Medical Center, Fort Lewis. Washington Am Fam Physician. 2014;89(5):359-366.

[Crossref]

02. National Asthma Education and Prevention Program. Expert Panel Report 3 (EPR-3)Guidelines for the diagnosis and management of asthma-summary report 2007. J Allergy Clin Immunol. 2007;120(5)S94-S138.

doi: [Article] [Crossref]

03. Vesbo J, Hurd SS, Agustí AG, Jones PW, Vogelmeier C, Anzueto A, et al. Global strategy for the diagnosis, management, and prevention of chronic obstructive pulmonary disease- GOLD executive summary. Am J Respir Crit Care Med. 2013;187(4)347-365.

doi: [Article] [Crossref]

04. Pellegrino R, Viegi G, Brusasco V, Crapo RO, Burgos $F$, Casaburi RE, et al. Interpretative strategies for lung function tests. Eur Respir J. 2005;26(5)948-968.

doi: [Article] [Crossref]

05. Standardization of spirometry, 1994 update. American Thoracic Society. Am J Respir Crit Care Med. 1995;152(3)1107-1136.

doi: [Article] [Crossref]

06. Celli BR, Decramer M, Wedzicha JA, Wilson KC, Agustí A, Criner GJ, et al. ATS/ERS Task Force for COPD Research- An official American Thoracic Society/European Respiratory Society statement research questions in chronic obstructive pulmonary disease. Am J Respir Crit Care Med. 2015;191(7)e2-e27.

doi: [Article] [Crossref]

07. Rahmanian SD, Wood KL, Lin S, King MA, Horne A, Yang S, Wu HM, Diaz PT. Gender differences in pulmonary function, respiratory symptoms, and macrophage proteomics among HIVinfected smokers. Scientifica. 2014. doi: [Article] [Crossref]
08. Ford ES, Mannino DM, Wheaton AG, Giles WH, Presley-Cantrell L, Croft JB. Trends in the prevalence of obstructive and restrictive lung function among adults in the United Statesfindings from the National Health and Nutrition Examination surveys from 1988-1994 to 20072010. Chest. 2013;143(5)1395-1406. doi: [Article] [Crossref]

09. Vandevoorde J, Verbanck S, Schuermans D, Kartounian J, Vincken W. Obstructive and restrictive spirometric patterns- fixed cut-offs for FEV1/FEV6 and FEV6. Europe Resp J. $2006 ; 27 ; 378-383$. doi: [Article] [Crossref]

10. Ferguson GT, Enright PL, Buist AS, Higgins MW. Office spirometry for lung health assessment in adults- a consensus statement from the National Lung Health Education Program. Chest. 2000;117(4)1146-1161. doi: [Article] [Crossref]

11. Tashkin DP, Celli B, Decramer M, Liu D, Burkhart D, Cassino $C$, et al. Bronchodilator responsiveness in patients with COPD. Eur Respir J. 2008;31(4)742-750.

doi: [Article] [Crossref]

12. Müller V, Gálffy G, Orosz M, Kovats Z, Odler B, Selroos $O$, et al. Characteristics of reversible and nonreversible COPD and asthma and COPD overlap syndrome patients- an analysis of salbutamol Easyhaler data. Int J Chron Obstruct Pulmon Dis. 2016;11;93-101. doi: [Article] [Crossref]

13. Postma DS, Reddel HK, ten Hacken $\mathrm{NH}$, van den Berge M. Asthma and chronic obstructive pulmonary disease- similarities and differences. Clin Chest Med. 2014;35(1)143-156. doi: [Article] [Crossref]

14. Janson C, Malinovschi A, Amaral AF, Accordini S, Bousquet J, Buist AS, et al. Bronchodilator reversibility in asthma and COPD- Findings from three large population studies. Europe Resp J. 2019;54(3)1900561. doi: [Article] [Crossref]

15. Barreiro TJ, Perillo I. An approach to interpreting spirometry. Am Fam Physician. 2004;69(5)1107-1114. [Crossref]

16. Aaron SD, Dales RE, Cardinal P. How accurate is spirometry at predicting restrictive pulmonary impairment?. Chest. 1999;115(3)869-873.

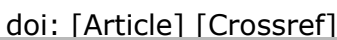


17. Boros P, Franczuk M, Wesołowski S. Mixed changes in spirometry- verification of the pattern of lung function impairment. Pneumonol Alergol Pol. 2003;71(11-12)527-532.

[Crossref]

18. Mapel DW, Dalal AA, Johnson $P$, Becker $L$, Hunter AG. A clinical study of COPD severity assessment by primary care physicians and their patients compared with spirometry. Am J Med. 2015;128(6)629-637.

doi: Epub 2015 Jan 13 [Article] [Crossref]
19. Safka KA, Wald J, Wang H, McIvor L, McIvor A. GOLD Stage and Treatment in COPD- A 500 Patient Point Prevalence Study. Chronic Obstr Pulm Dis. 2017;4(1)45-55.

doi: [Article] [Crossref]

20. Haughney J, Gruffydd-Jones K, Roberts J, Lee AJ, Hardwell A, McGarvey L. The distribution of COPD in UK general practice using the new GOLD classification. Europe Resp J. 2014;43(4)993-1002.

doi: [Article] [Crossref] 